International Journal of Mechanical Engineering and Technology (IJMET)

Volume 11, Issue 11, November 2020, pp. 6-15, Article ID: IJMET_11_11_002

Available online at https://iaeme.com/Home/issue/IJMET?Volume=11\&Issue=11

ISSN Print: 0976-6340 and ISSN Online: 0976-6359

DOI: https://doi.org/10.34218/IJMET.11.11.2020.002

(C) IAEME Publication

Scope Database Indexed

\title{
STRUCTURAL ANALYSIS OF SLEWING BEARINGS FOR WIND TURBINES
}

\author{
J.H Kang, S.J Heo, J.H Yu and H.W Lee* \\ Department of Aeromechanical Engineering, Jungwon University, South Korea \\ *Corresponding Author
}

\begin{abstract}
This study is a structural analysis of slewing bearings for wind turbines. The ball of a bearing delivers load while making contact with raceways of the inner and outer rings. To facilitate stress analysis of the slewing bearing, which has more balls than other types of bearing, the balls were converted into spring elements. Considering the shape of contact between balls and raceways, one, two, and three spring elements were introduced. Global finite element analysis of the bearing, with balls as spring elements, showed that the bearing experienced different degrees of deformation depending on the number of springs. Using the bearing deformation obtained from the global analysis, cut boundary constraint was applied for local contact analysis of balls and raceways. The contact stress between balls and raceways showed that more uniform stress could be achieved by increasing the number of springs.
\end{abstract}

Keywords: Slewing bearing, Contact stress, Finite element analysis, spring element, Wind turbine.

Cite this Article: J.H Kang, S.J Heo, J.H Yu and H.W Lee, Structural Analysis of Slewing Bearings for Wind Turbines. International Journal of Mechanical Engineering and Technology. 11(11), 2020, pp. 6-15.

https://iaeme.com/Home/issue/IJMET?Volume=11\&Issue=11

\section{INTRODUCTION}

Slewing bearings for wind turbine are comprised of a pitch bearing, which adjusts the blade angle while connecting the blade and hub, and a yaw bearing, which adjusts the nacelle in the wind direction while connecting it to the tower. Figure 1 shows the assembly position of the bearing for a wind turbine.

While rolling bearings support rotational movement along the axis, slewing bearings are commonly used in cranes and turrets, and are subject to high turnover moment as the load acts further away from the bearing point. Due to this turnover moment, the contact point of the ball and raceway shifts to the end. This results in local truncation, which involves high stress and shortens bearing life. Bearing life is calculated using basic load ratings and bearing equivalent operating load under static and dynamic conditions [1, 2]. However, this standard 
is limited to ball bearings, roller bearings, and thruster bearings. Bearing life may be difficult to calculate in the case of other bearing designs, and techniques like finite element analysis are required for design verification.

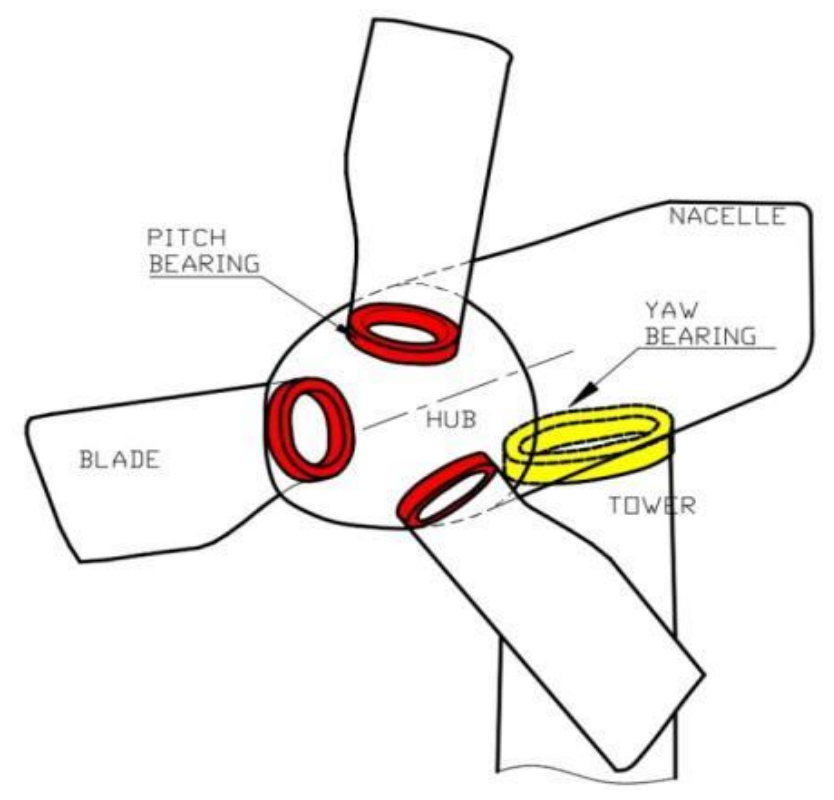

Figure 1 Assembly of slewing bearing for wind turbine

A large slewing bearing has balls and raceways in a 4 point contact structure, and rows may be added to carry heavy loads. A bearing with many balls will have many contact points, making analysis more complicated. A compact mesh is needed for precise stress analysis due to point contact between balls and raceways, and this translates to a longer analysis time.

To address the above issues, researchers have proposed a method of conducting finite element analysis with balls as non-linear spring elements. Zupan[3] et al. replaced balls with spring elements, and proposed a model that calculates change in contact angle using the displacement of points in contact with spring elements when a load is applied. Daidie[4] et al. modeled ball bearings as non-liner spring elements, and employed the finite element method to calculate the reaction force acting on springs and contact angles. Gao[5] modeled the inner and outer rings of a slewing bearing as an 8 node hexahedral mesh, and analyzed bearing behavior by substituting balls with non-linear spring elements connecting contact points. Jon Plaza[6] et al. enhanced the precision of analysis by applying a structure comprised of nonlinear spring elements, rigid beam elements, and rigid surface elements to the deformation behavior of bearings in wind turbines. Schwack[7] et al. used finite element analysis to examine the effect of contact angle on contact stress in the design verification of a 2 row 4 contact bearing in a $7.5 \mathrm{MW}$ wind turbine. The analysis showed that stress is concentrated at raceway ends of conventional slewing bearings due to truncation error, and that contact stress levels are relatively high.

This study adopted Gao's approach among methods of substituting balls with non-linear springs for stress analysis of wind turbine bearings, and performed finite element analysis. Because balls and raceways establish line contact instead of point contact due to the prestressed state of the bearing, this study introduced two, and three spring elements, and compared the results to that of Gao. Cut boundary constraint, which performs local modeling of balls and rings and uses displacement from global analysis as boundary condition, was applied. Contact stresses of balls and raceways were calculated under the three conditions, and stress levels were compared in relation to number of springs. 


\section{FINITE ELEMENT ANALYSIS OF PITCH BEARING}

\subsection{Pitch bearing dimensions for wind turbine}

The pitch bearing of this study, used in $4 \mathrm{MW}$ wind turbines, has an outer ring diameter of $\phi$ $3020 \mathrm{~mm}$, inner ring diameter of $\$ 2479 \mathrm{~mm}$, and height of $300 \mathrm{~mm}$. The size of the ball is $82.55 \mathrm{~mm}$, and 93 balls were assembled in each row, amounting to a total of 186 balls. The raceway has a typical slewing structure, with both outer and inner rings having a constant inner diameter. The raceway making contact with balls has a radius of $\mathrm{R} 42.93 \mathrm{~mm}$, and the center is the point with an offset of $a=1.09 \mathrm{~mm}$ and $b=1.30 \mathrm{~mm}$. A cross-sectional view of the bearing used in this study is presented in Figure 2.

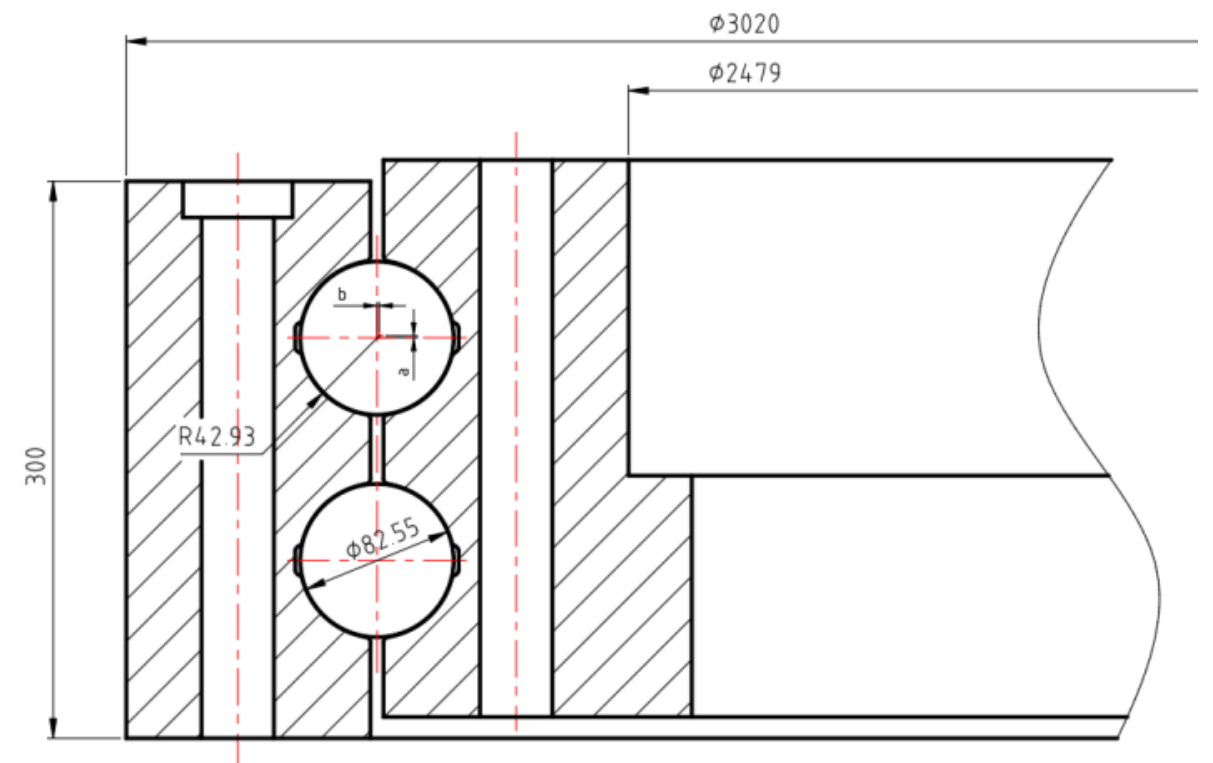

Figure 2 Cross-section and dimensions of the bearing

\subsection{Spring elements as ball substitutes}

Balls in a ball bearing act as rolling elements. They allow inner and outer rings to engage in relative motion, and deliver power when the bearing is under an external load. In Figure 2, the center of the raceway is a, b away from the center of the ball, and the radius of the raceway is larger than the radius of the ball, which is $\mathrm{R} 41.275 \mathrm{~mm}$. A magnified view shows the interference geometry of the ball and raceway, as presented in Figure 3. As such, the slewing bearing is a prestressed bearing that applies compressive stress between the raceway and ball. The ball and raceway changes from point contact to line contact.

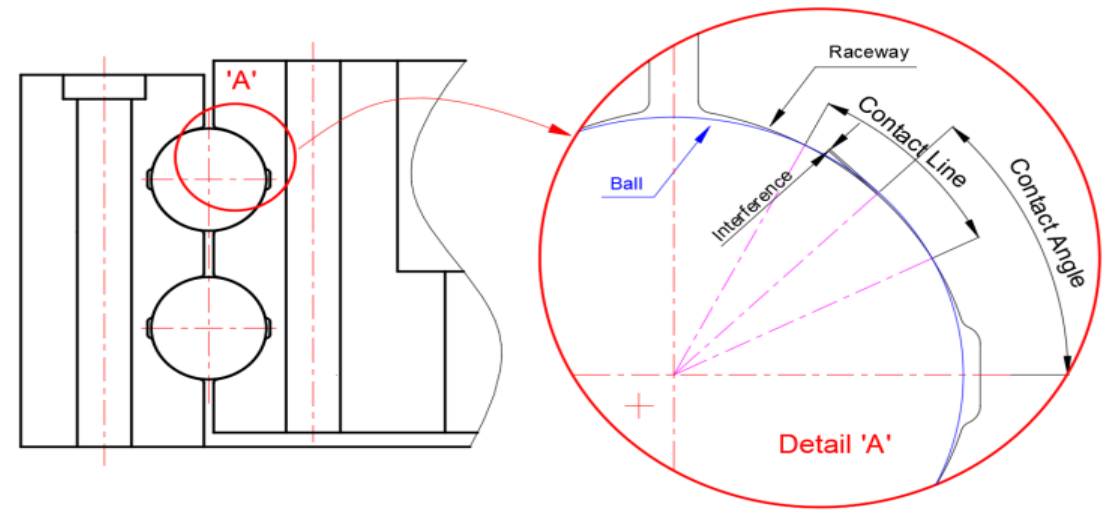

Figure 3 Interference geometry of ball and raceway 


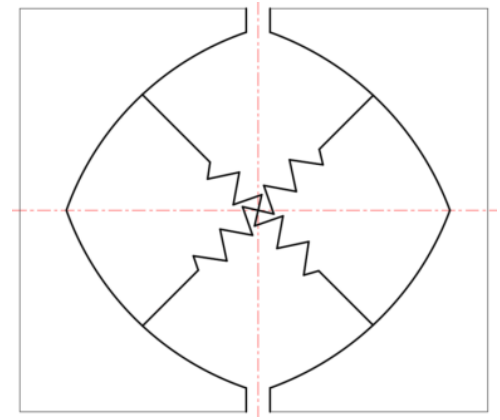

(a) Gao's ball replacement method

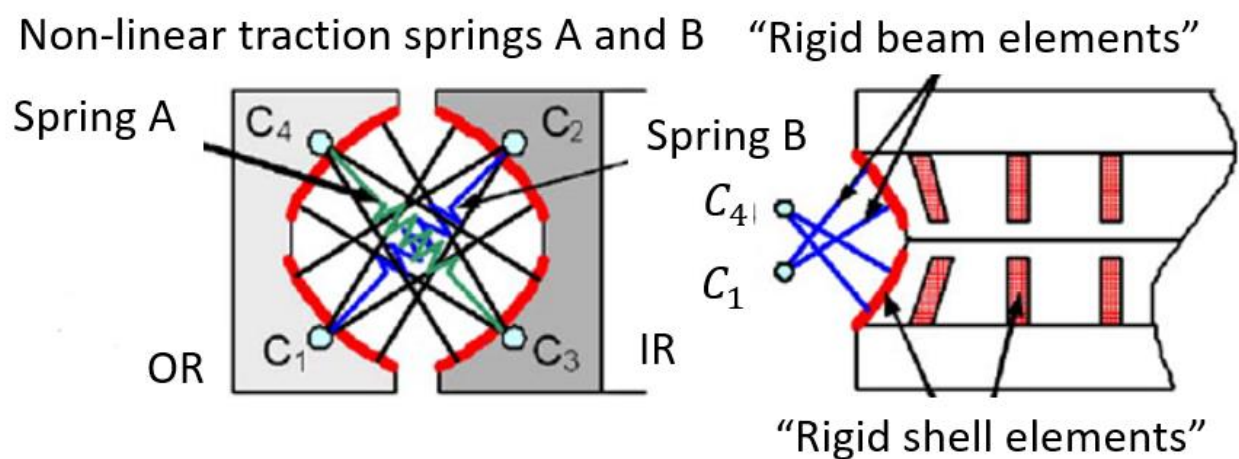

(b) Daidie's ball replacement method
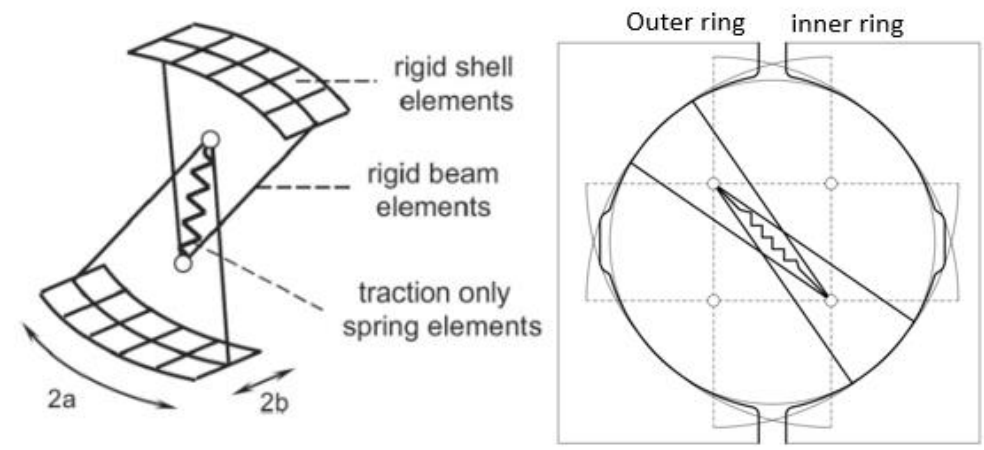

(c) Plaza's ball replacement method

Figure 4 Replacement of balls with spring elements in past research

Figure 4 shows methods of using spring elements to replace balls in contact with raceways, as proposed by Gao, Daidie, and Plaza. Gao's method in Figure 4(a) uses a spring element to connect the point where contact angle and raceway meet. Daidie's method in Figure 4(b) uses spring elements to connect the offset raceway center. The center and raceway are connected by two rigid elements. Plaza's method in Figure 4(c) assembles rigid shell elements and rigid beam elements and connects raceway centers with spring elements. In the case of Gao's model, the contact angle changes significantly if there is a large displacement of the inner and outer rings. Load support by the primary spring element becomes difficult, and this increases the likelihood of overestimating displacement. On the other hand, the methods proposed by Daidie and Plaza were expected to have better precision, but more challenging to use in generating models. Plaza's method was more complicated than Daidie's due to the use of rigid shells for additional contact between raceways and balls. 
As shown in Figure 5, this study proposed using two spring elements at both ends of the contact line and three spring elements at the contact angle and both ends of the contact line to solve the problem of Gao's one spring element method, namely, the increase in deformation with changes in contact angle.

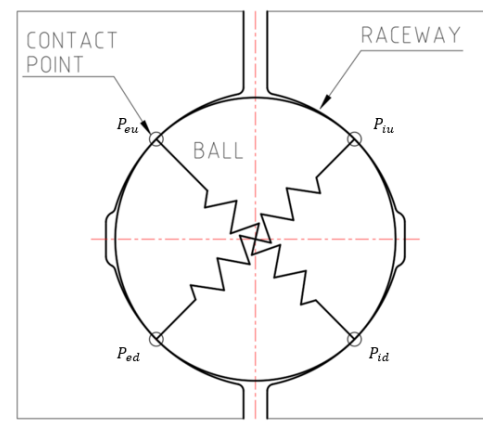

(a) One spring element

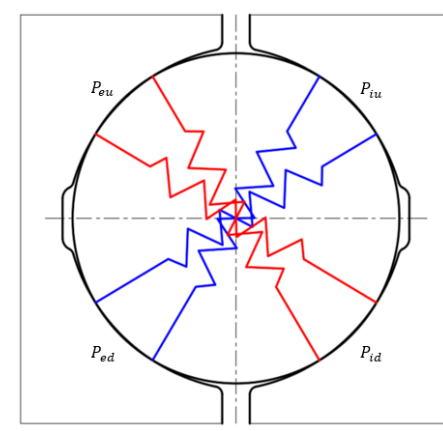

(b) Two spring elements

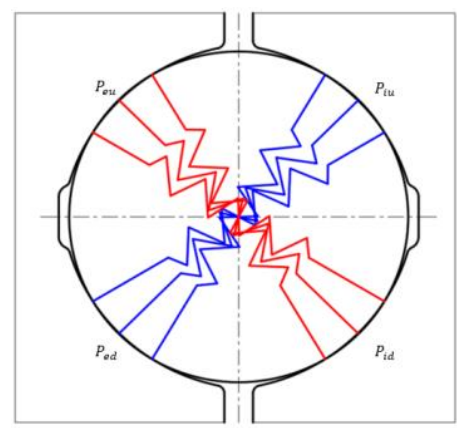

(c) Three spring elements

Figure 5 Method of ball replacement for bearing structural analysis

\subsection{Global analysis with spring element}

The finite element analysis model was a hexahedron with 1/104 bearing as there were 104 bolt holes. This was copied along the z-axis and merged in APDL. The mesh of the 1/104 model was comprised of 27,375 nodes and 5,680 solid 185, while the mesh of the full bearing was a hexagonal element comprised of 1,869,920 nodes and 408,096 elements. The hub where the bearing is assembled had a tetrahedron mesh comprised of 294,66 nodes and 101,493 elements. To simplify the analysis, linear tetrahedron elements were used as shown in Figure 6.

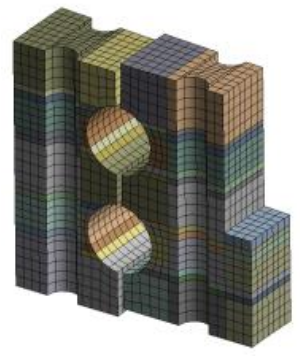

(a) $1 / 104$ Bearing

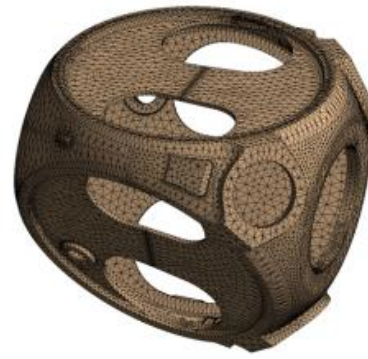

(b) Hub

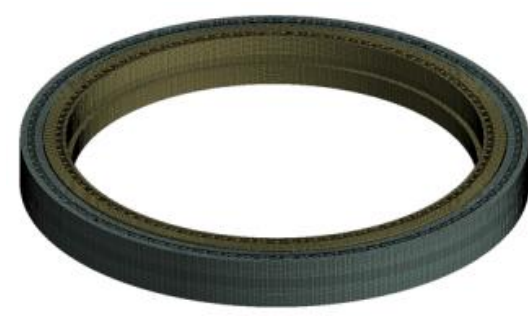

(c) Bearing full model

Figure 6 Mesh System of bearing and hub

As shown in Figure 7(a) and (b), analysis was performed by connecting the inner and outer rings of the bearing with non-linear springs. The connecting joint of the hub and main shaft was subject to boundary conditions. As shown in the figure, the ultimate load or moment, axial load, and shear load acting on the bearing were $16,673.6 \mathrm{kNm}, 671.1 \mathrm{kN}$, and $527,2 \mathrm{kN}$, respectively. 

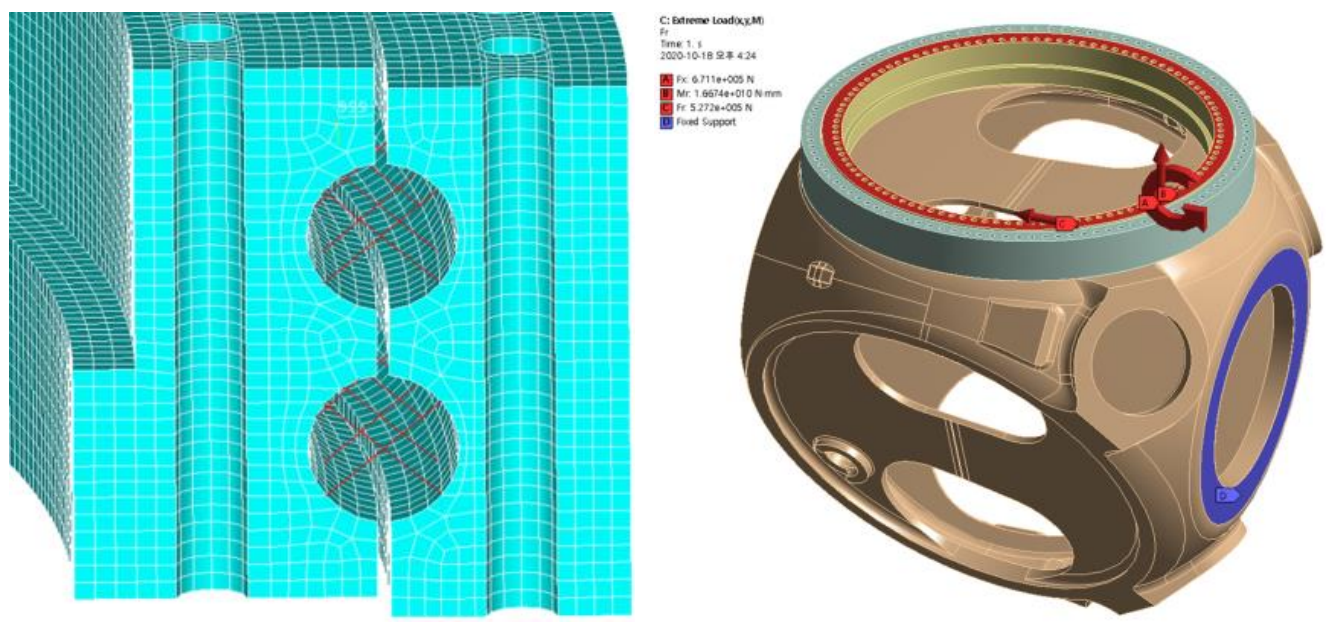

(a) One spring connection (b) Full model with force and boundary conditions

Figure 7 Global analysis preparation to analyze bearing deformation

Figure 8 shows the displacement and stress of the outer raceway, obtained by analyzing the full model with one, two, and three spring elements. The maximum displacement was observed for the inner ring, and displacement decreased from $6.1393 \mathrm{~mm}, 5.5605 \mathrm{~mm}$, to $5.4278 \mathrm{~mm}$ as the number of springs increased. The stress experienced by the area connected to springs also decreased gradually, recording $1342.6 \mathrm{MPa}, 906.14 \mathrm{MPa}$, and $540.96 \mathrm{MPa}$, respectively.

In the full model analysis, the greatest stress was observed at the point with the largest displacement. Two bolt holes were cut from the area subject to the greatest stress to apply the cut boundary constraint method. The mesh system and boundary conditions for local analysis are presented in Figure 9(a). The mesh was a combination of hexahedral and tetrahedral meshes, and the mesh of the area connecting the balls and raceways was divided to $1.5 \mathrm{~mm}$. It was comprised of a total of 2,997,314 nodes and 1,775,080 elements. Figure 9(b) shows the mesh with the cut boundary displacement applied.

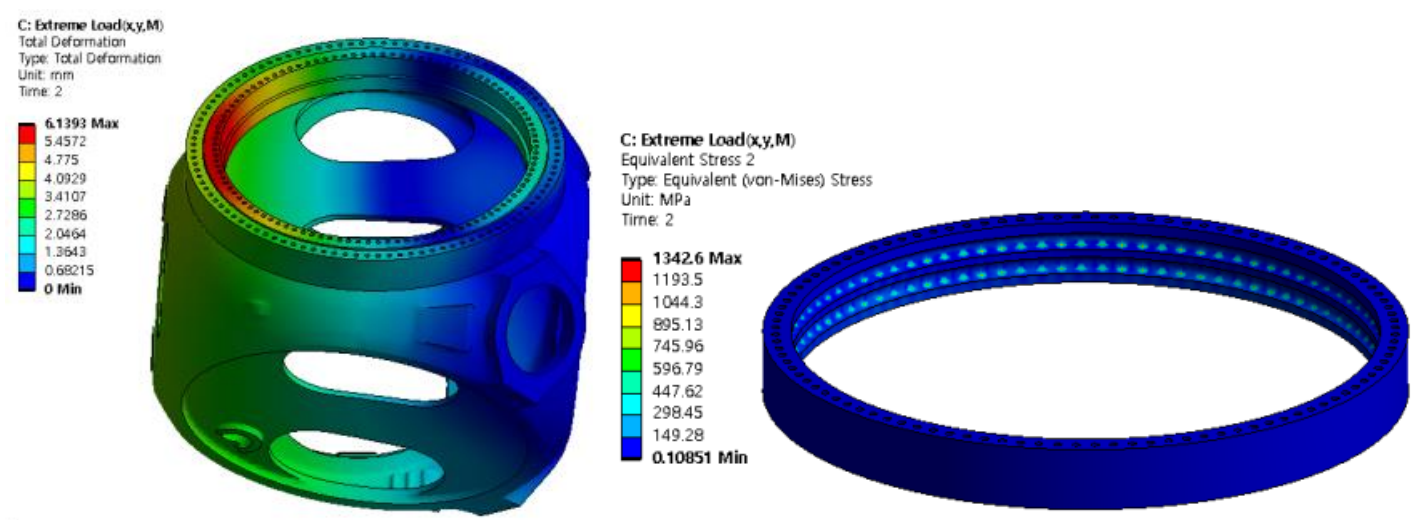

(a) One spring element connection 


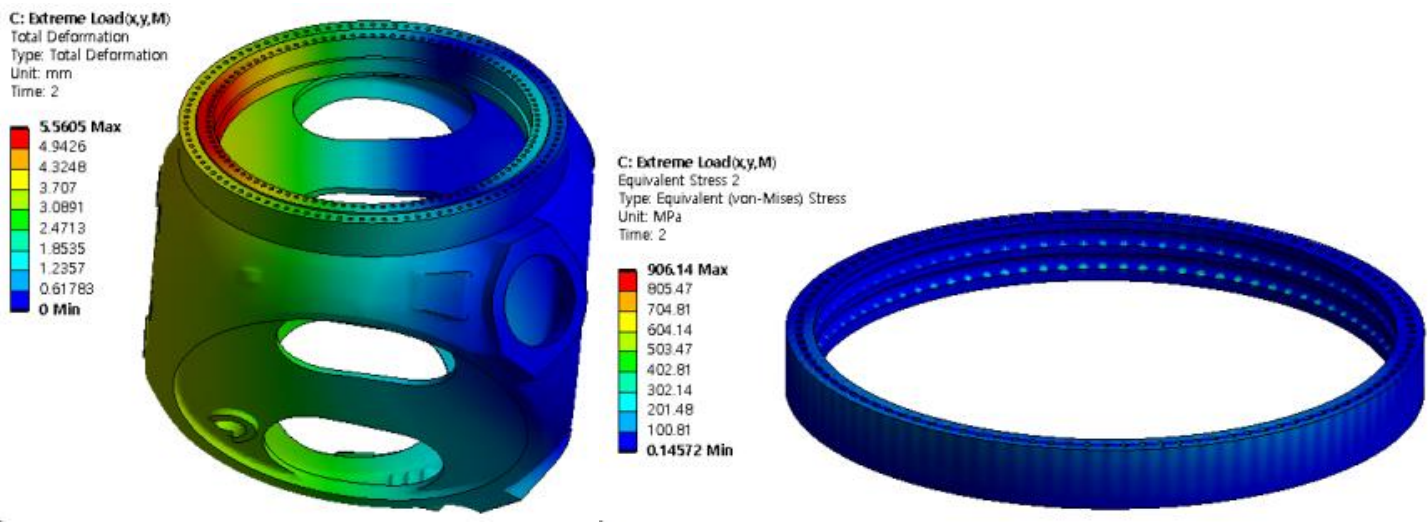

(b) Two spring element connection

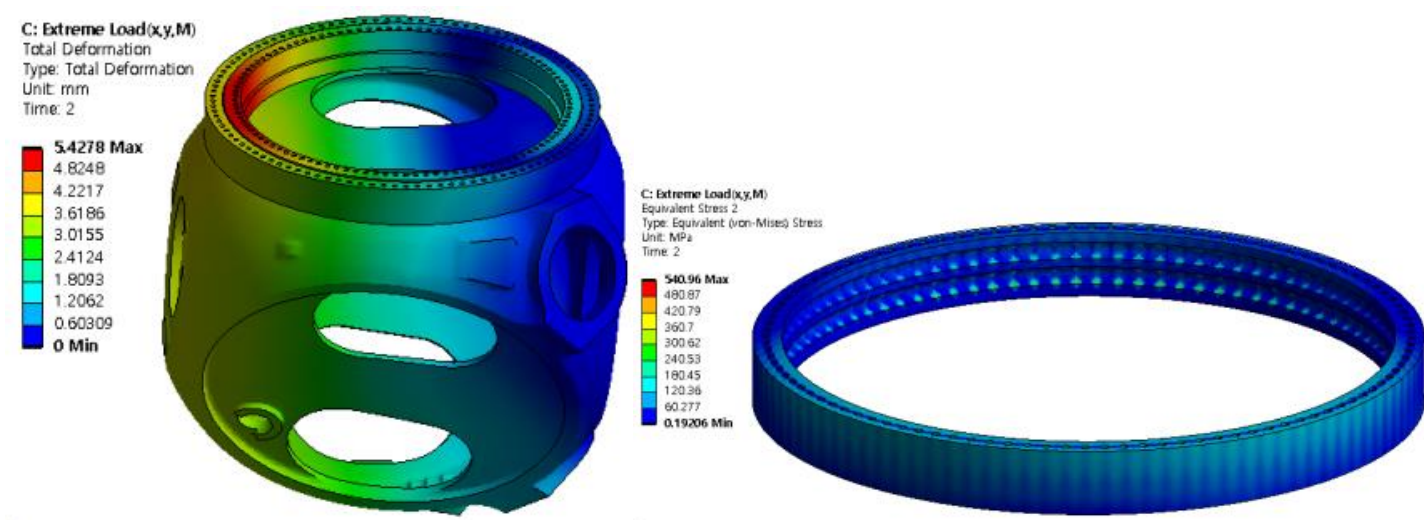

(c) Three spring element connection

Figure 8 Full model analysis results using spring elements

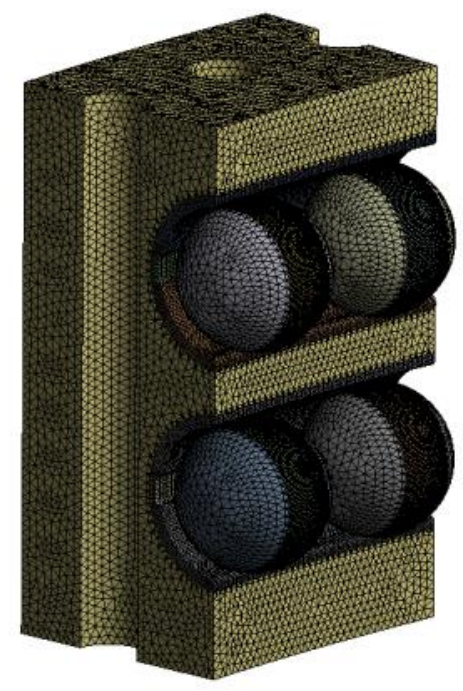

(a) Mesh system

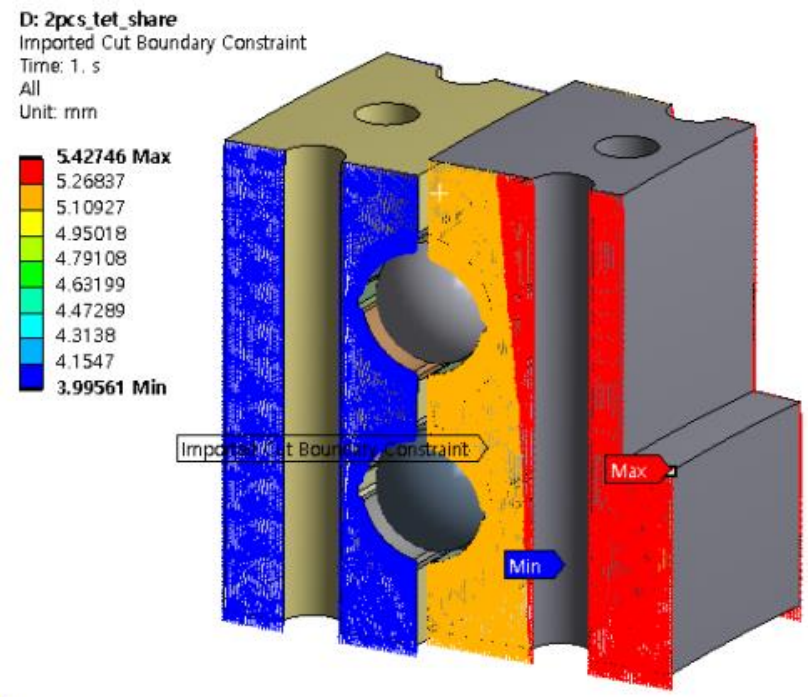

(b) Cut boundary constraint

Figure 9 Mesh system and boundary conditions for local analysis

Figure 10 shows the contact stress of balls and raceways under the cut boundary constraint. For one spring, the contact stress of the outer ring, inner ring, and ball was 7912MPa, 7437.8MPa, and 7068.2MPa as shown in Figure 10(a). For two springs, the contact stress values were 2294.5MPa, 2302.3MPa, and 2271.1MPa. For three springs, the contact 
stress values were 2075.1MPa, 2045.4MPa, and 1847.6MPa as shown in Figure 10(c). The stress distribution of bearing components for the different number of spring elements is summarized in Table 1.

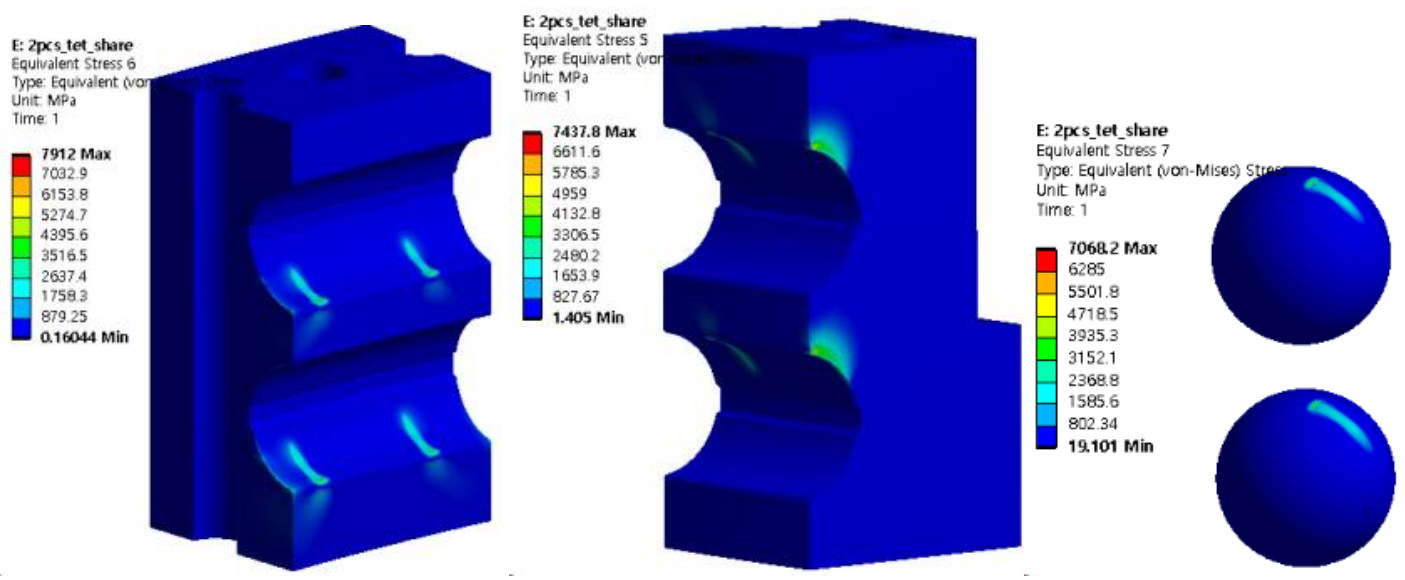

(a) One spring element connection

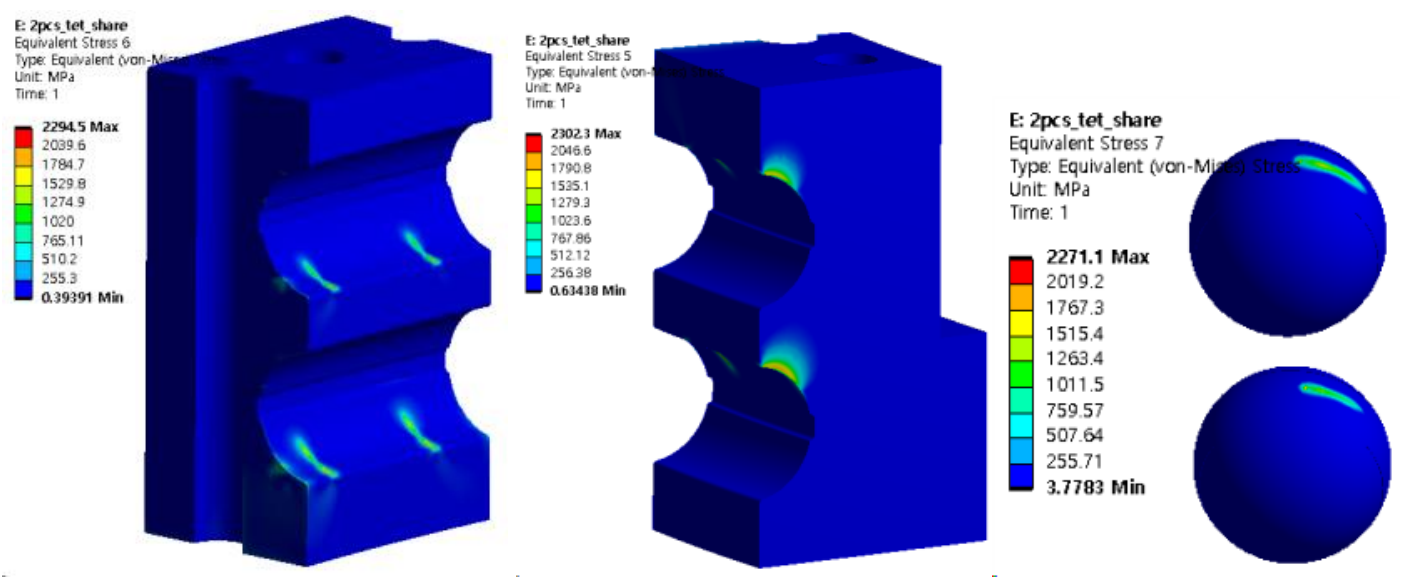

(b) Two spring element connection
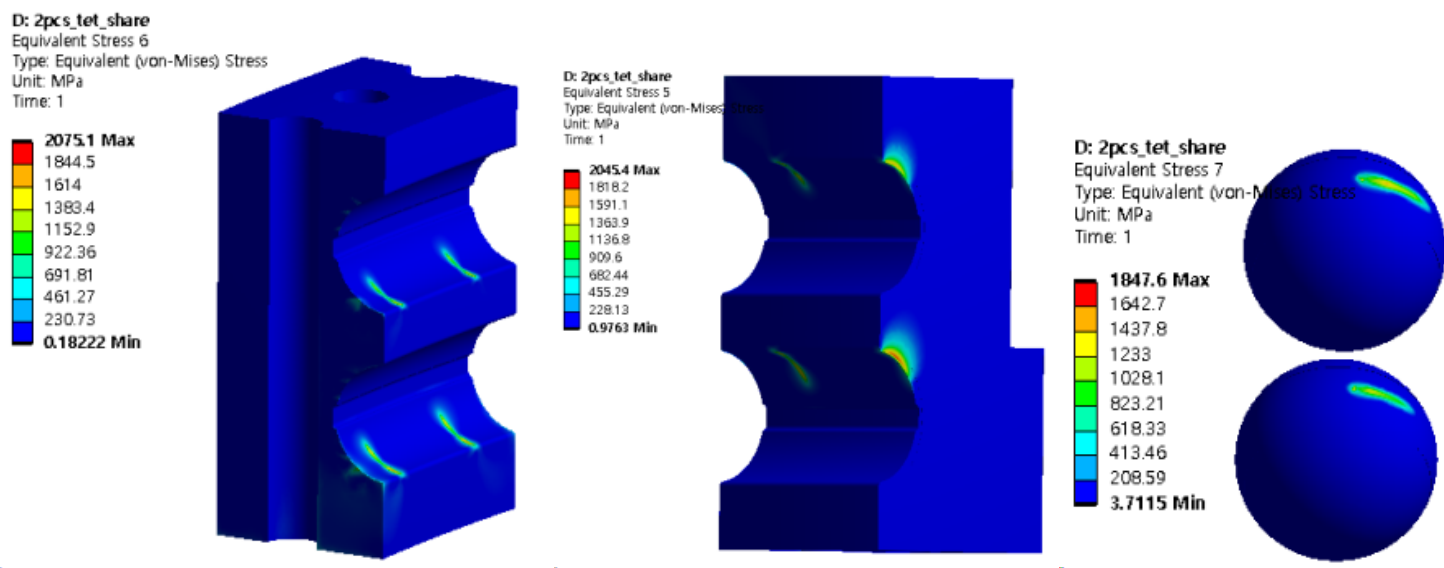

(c) Three spring element connection

Figure 10 Results of contact stress analysis through local analysis 
Table 1 Maximum equivalent stress in relation to bearing analysis conditions

\begin{tabular}{|l|c|c|c|}
\hline & $\begin{array}{c}\text { Outer ring raceway } \\
\text { (MPa) }\end{array}$ & $\begin{array}{c}\text { Inner ring raceway } \\
\text { (MPa) }\end{array}$ & $\begin{array}{c}\text { Ball } \\
\text { (MPa) }\end{array}$ \\
\hline One spring element & 7912.0 & 7437.8 & 7068.2 \\
\hline Two spring elements & 2294.5 & 2302.3 & 2271.1 \\
\hline Three spring elements & 2075.1 & 2045.4 & 1947.6 \\
\hline
\end{tabular}

As shown in Table 1, there is greater deformation with changing contact angle when there is only one spring element, which also results in high contact stress. The change in stress was not that significant when two or three spring elements were used. For bearing analysis using spring elements, at least two springs should be used to counter the change in contact angle.

\section{CONCLUSION}

To analyze contact stress between balls and raceways of a wind turbine bearing, this study analyzed displacement by substituting the first ball with a spring element, and calculated contact stress by locally cutting balls and raceways at the point subject to the greatest stress in global bearing analysis. The following conclusions were derived.

1) Under the one spring element connection method, which replaces balls with a spring element in global finite element analysis, the largest displacement of $6.139 \mathrm{~mm}$ was observed since the spring element can only support load in the axial direction when the bearing is subject to a load and contact angle changes.

2) Since the slewing bearing is a prestressed bearing, the ball and raceway establishes line contact instead of point contact. When balls are substituted with two or three spring elements, displacement decreases to $5.5605 \mathrm{~mm}$ and $5.4278 \mathrm{~mm}$, respectively, since the load can be supported by the remaining springs, unlike the one spring element connection.

3) After calculating the global displacement for the three different conditions of spring connection, modeling was performed with two bolt holes cut from the area subject to the greatest stress. The cut boundary constraint technique was used to calculate the contact stress between the balls and raceways. The stress under one spring element was $7912 \mathrm{MPa}$, which was difficult to comprehend. However, the values were more acceptable, between 2000 and $2300 \mathrm{MPa}$, for the two and three spring elements.

4) When substituting balls only with spring elements for bearing stress analysis, at least two spring elements must be used to obtain reasonable values for displacement and contact stress.

\section{ACKNOWLEGEMENT}

This work was supported by the Korea Institute of Energy Technology Evaluation and Planning (KETEP) and the Ministry of Trade, Industry \& Energy (MOTIE) of the Republic of Korea (No. 20173030024670).

\section{REFERENCES}

[1] ISO 76: 2006. Rolling bearings - Static load ratings.

[2] ISO 281: 2007. Rolling bearings - Dynamic load ratings and rating life.

[3] Zupan, S., and Prebil, I. Carrying angle and carrying capacity of a large single row ball bearing as a function of geometry parameters of the rolling contact and the supporting structure stiffness. Mech Mach Theory, 36(10), 2001, pp.1087-1103.

[4] Daidié, A., Chaib, Z., and Ghosn, A. 3D simplified finite elements analysis of load and contact angle in a slewing ball bearing. ASME J Mech Des, 130(8), 2008, pp.082601. 
[5] Gao, X.H., Huang, X.D., Wang, H. and Chen, J. Modelling of ball raceway contacts in a slewing bearing with nonlinear springs. Proc Inst Mech Eng Part C, 225(4), 2011, pp.827831.

[6] Plaza, J., Abasolo, M., Coria, I., Aguirrebeitia, J. and Ferna'ndez de Bustos I. A new finite element approach for the analysis of slewing bearings in wind turbine generators using superelement techniques. Meccanica, 50, 2015, pp.1623-1633.

[7] Schwack, F., Flory, H., Poll, G. and Stammler, M. Free contact angles in pitch bearings and their impact on contact and stress conditions. Wind Eur. SUMMIT 2016, Hamburg, 2016 pp. 27-29. 